\title{
Mateusz Felczak
}

Uniwersytet SWPS

\section{Audiosfery lochów, poetyki krajobrazu. Ślady estetyk romantyzmu w grach cRPG}

Od połowy minionej dekady na przecięciu gier cyfrowych, tradycyjnych gier RPG oraz niszowych inicjatyw muzycznych daje się zauważyć wzrost zainteresowania historycznie istotnymi i nieco zapomnianymi konwencjami uczestnictwa w popkulturze. Rok 2015 znaczą premiery Critical Role, internetowego serialu opartego o nagrania z sesji Dungeons \& Dragons, oraz Pillars of Eternity, produkcji stawiającej sobie za cel wskrzeszenie świetności gier bazujących na silniku Infinity, a więc będących próbą przeniesienia kolejnych wersji niezwykle popularnego systemu autorstwa Gary'ego Gygaxa i Dave’a Arnesona na komputery osobiste. Wraz z komercyjnym renesansem franczyz czerpiących z Lochów i smoków na rynku pojawiły się kolejne gry cyfrowe nawiązujące do estetyki czy nawet mechaniki takich produkcji cRPG jak Baldur's Gate (1998) bądź Icewind Dale (2000). Nastąpił medialny triumf pewnego typu doświadczenia związanego $\mathrm{z}$ obszarem gier cyfrowych $-\mathrm{z}$ jednej strony mocno zakorzenionego $\mathrm{w}$ specyficznie pojmowanej nostalgii, z drugiej zaś powiązanego z dyskursywną nobilitacją określonych konwencji estetycznych. Niniejszy artykuł jest próbą wyróżnienia $\mathrm{i}$ analizy audiowizualnych dominant estetycznych wyłaniających się z tak zarysowanego kontekstu w wybranych grach cRPG, ze szczególnym uwzględnieniem tytułów wykorzystujących konwencję fantasy. Nadrzędnym jego celem jest zwrócenie uwagi na pewną ciągłość i żywotność inspiracji estetycznych przejawiających się na polu malarstwa, gier oraz muzyki. 
Tekst ten kategoryzuje pewien typ gier fantasy RPG jako teksty kultury zarazem czerpiące z postaw filozoficznych rozwijanych w obrębie (neo)romantycznych konwencji wizualnych, jak i inspirujące utwory na pograniczu sztuk. Historyczny filar analizy wybranych gier cyfrowych stanowi estetyka amerykańskiego malarstwa pejzażowego - przede wszystkim luminizmu i przedstawicieli Hudson River School. Z kolei wpływ produkcji cRPG na inne dziedziny aktywności artystycznej zarysowano na przykładzie subgatunku muzyki elektronicznej noszącego nazwę dungeon synth. Trzy kolejne podrozdziały tekstu skupiają się, kolejno, na zarysowaniu podstawowych pojęć oraz kontekstu poetyk wizualnych amerykańskiej szkoły pejzażowej połowy XIX wieku, uchwyceniu wpływu wypracowanych na gruncie Hudson River School estetyk wizualnych na gry cRPG oraz rozwoju tych inspiracji w sferze audiowizualnej gatunku dungeon synth.

Dziedzictwo romantyzmu w filozofii oraz sztukach wizualnych jest w oczywisty sposób zagadnieniem bardzo szerokim i obejmującym odłamy, wersje i prądy mocno zróżnicowane tak pod względem geograficznym, jak i kulturowym. Skupienie się głównie na refleksji myślicieli oraz artystów amerykańskich podyktowane jest dwiema naczelnymi przesłankami. Po pierwsze, jak słusznie notuje Maria B. Garda, „gry cRPG narodziły się między Los Angeles i Nowym Jorkiem" (Garda, 2016, s. 82), a ich wywodząca się z tamtejszego kręgu kulturowego poetyka obrazowania - jak chciałbym argumentować - została w twórczy sposób przejęta i rozwinięta na gruncie europejskim oraz azjatyckim. Po drugie, interesujące mnie zjawiska z pogranicza muzyki i sztuk wizualnych (jak dungeon synth) przeżywają obecnie swój rozkwit właśnie na kontynencie amerykańskim. Należy też zaznaczyć, że rozwinięcie szczegółowych kwestii genologicznych związanych z ustaleniem granic gatunku cRPG wymagałoby osobnego studium. Przedstawicieli tego gatunku będę więc wyróżniał na podstawie elementów dystynktywnych, które są istotne z punktu widzenia stawianego $\mathrm{w}$ artykule celu, jakim jest omówienie inspiracji estetycznych w powiązaniu z kluczowymi komponentami rozgrywki, takimi jak eksploracja, rozwój postaci oraz manipulacja przedmiotami (por. Vargas-Iglesias, 2020, s. 171).

\section{Fantasy, amerykański romantyzm i gry cRPG}

Mianem Hudson River School określa się nurt amerykańskiego malarstwa pejzażowego, którego największy rozkwit przypadał na połowę XIX wieku. Jego nazwa wywodzi się od regionu geograficznego Stanów Zjednoczonych o ważnym znaczeniu historycznym i wyjątkowych właściwościach estetycznych. Chociaż najbardziej znane płótna artystów związanych ze Szkołą Rzeki Hudson niekoniecznie prezentowały wizje amerykańskiego pogranicza, to ich wpływ i recepcję 
znaczą rozwijane najmocniej na gruncie amerykańskiego neoromantyzmu idee związane z namysłem nad pięknem naturalnego środowiska, budowaniem określonej tożsamości na zasadzie związku z przyrodą oraz nieironicznym czytaniem natury jako rodzaju przepełnionego ukrytą metafizyką „religijnego palimpsestu" (Novak, 2007, s. XIX). Charakter artystycznych wizji twórców takich jak Frederic Edwin Church czy John Frederick Kensett przejawiał się tak w formie, jak i treści: wielkoformatowe płótna, ewokujące potęgę natury, prezentowały ją jednocześnie w kontekście niemożliwej do okiełznania siły, aktywnie - w myśl filozoficznej koncepcji natura naturans, na gruncie amerykańskim zaszczepionej głównie przez recepcję pism Samuela Taylora Coleridge’a (zob. Harvey, 2013) - ewoluującej i skrywającej w sobie sprawczą energię życiową. Popularność tej estetyki obrazowania i myślenia o krajobrazie wykracza poza wiek XIX i utrwaliła ona swój wpływ w licznych tekstach kultury, ze szczególnym uwzględnieniem literatury i gier fantasy, które chętnie sięgały po wypracowane w jej obrębie sugestywne narzędzia ekspresji artystycznej.

Od pewnego momentu prace groznawcze zaczęły traktować sferę audiowizualną i obszar rozgrywki jako powiązane ze sobą elementy (Hutchison, 2008), uwypuklając tym samym ich symultaniczne współoddziaływanie na proces interakcji z grą. Podnoszenie estetyki do rangi co najmniej równoważnego mechanice pola generowania znaczeń zaowocowało także próbami wykorzystania jej w dociekaniach genologicznych (Karhulahti, 2011). Szerszy problem rozumienia estetyki w grach cyfrowych bywał również rozpatrywany z perspektywy dość precyzyjnych podziałów, jak postulowane przez Simona Niedenthala rozróżnienie na trzy aspekty estetyki gier: elementy oddziałujące na zmysły graczy, elementy budujące szczególne doświadczenie estetyczne oraz punkty wspólne gier z innymi dziełami sztuki (Niedenthal, 2009).

Wybierając do analizy gry operujące poetyką fantasy, podążam za intuicją badawczą Tomasza Z. Majkowskiego, który w kontekście literaturoznawczym rozpoznaje w tym gatunku ,realizację pewnego postulatu, artystycznego manifestu" (Majkowski, 2013, s. 18), stanowiącego o przynależności poszczególnych utworów do tego obszaru ekspresji artystycznej. Poetyka fantasy (szczególnie na polu eksploatacji muzycznej) jest w powiązaniu z inspiracjami (neo)romantycznymi wyborem bardzo świadomym i organizującym układ wielu tekstów kultury funkcjonujących na pograniczach audiosfery i wizualnej kultury fanowskiej. Maria B. Garda, badaczka zajmująca się ongiś fantasy w kontekście gier cyfrowych, pisała z kolei: „fantasy jest dla mnie głęboko nostalgiczne - w wymiarze kulturowym, gdyż stanowi fascynację przedindustrialnym obrazem Europy wywołanym przez romantyzm" (Garda, 2016, s. 46). Uwagi obojga badaczy wy- 
znaczają obszar zainteresowania tego krótkiego studium. Nie podejmując więc nowych rozstrzygnięć dotyczących zakresu pojęcia fantasy w odniesieniu do gier cyfrowych, poprzestanę na wskazaniu elementów tejże poetyki, które stanowią wspólne punkty odniesienia dla wymienianych wcześniej trzech obszarów ekspresji artystycznej (malarstwa, muzyki oraz gier). Samo pojęcie estetyki w świetle tradycji filozoficznej, która stanowiła główny punkt odniesienia dla interesujących mnie tradycji luminizmu i nurtów malarstwa pejzażowego o proweniencji romantycznej, jest traktowane dość szeroko, a nawet „pozostaje celowo niedookreślone i szerokie" (Guardiano, 2017, s. XVII).

\section{Poetyki wizualne}

Monumentalne pejzaże, landszafty z zagubionymi w nich pojedynczymi postaciami ludzi i zwierząt, obiekty natury poddane działaniu światła, które wydobywa bądź ukrywa w utrwalonym na płótnie momencie ich właściwości - tak można pokrótce przedstawić zbiór najczęstszych skojarzeń powiązanych z dokonaniami malarzy ze Szkoły Rzeki Hudson i romantycznych luministów. Filozoficzne podwaliny malarskiego transcendentalizmu, sytuowane przez Nicolasa Guardiano w koncepcjach Ralpha Waldo Emersona i Charlesa Sandersa Peirce’a, wychodzą z założenia o niemal permanentnym zanurzeniu (immersji) podmiotu w otaczającej go naturze. Od indywidualnych usposobień postrzegającego podmiotu zależy, czy - i jakie - elementy świata zostaną przezeń zauważone i włączone w obszar krytycznej refleksji (Guardiano, 2017, s. 3). Wrażliwość obserwacji można więc wykształcić, a egzystencjalna formacja jednostki poprzez obcowanie z naturą dokonuje się na zasadzie „zwykłego i natychmiastowego [jej] doświadczania” (Guardiano, 2017, s. 6).

Skupienie na przyrodzie nie oznacza bynajmniej, że romantyczne amerykańskie malarstwo pejzażowe było wolne od związków z polityką. I tak, najbardziej znana wersja obrazu Cotopaxi Frederica Edwina Churcha (1862) zyskała uznanie ze względu na jej odczytanie w kontekście wojny secesyjnej. Tytułowy ekwadorski wulkan uchwycony w momencie erupcji dzieli przestrzeń płótna na obszary panowania światła i ciemności; kolorystyczne kontrasty podkreślają agonistyczną dynamikę sceny, zachowującej przy tym wewnętrzną symetrię. Odczytanie estetyki w kluczu etycznym, z wyrazistymi podziałami i widocznymi granicami, w pewnej mierze pozostaje dziedzictwem wykorzystywanym w graficznej retoryce współczesnych gier RPG. Nawet dość jednolite pod względem palety kolorystycznej produkcje, jak The Elder Scrolls IV: Oblivion (2006) czy Dragon Age: Inquisition (2014), w określonych okolicznościach fabularnych uruchamiają filtry zmieniające estetykę poszczególnych obszarów gry w sposób analogiczny do zmiany błękit- 
nego nieba na zasnute wulkanicznym dymem słońce w Cotopaxi. Paul Martin argumentował, że w przypadku czwartej części serii The Elder Scrolls transformacja krajobrazu przesuwa jego projektowane odczytanie z pola wzniosłości (sublime) na pole malowniczości (picturesque), za czym miałaby podążać narracja ilustrująca negatywnie ewaluowaną przemianę pastoralnej idylli w quasi-industrialną antyutopię (Martin, 2011). Brytyjski badacz przeciwstawia znaczącą estetykę krajobrazu stereotypowemu i pełnemu gatunkowych klisz przedstawieniu w grze postaci niezależnych oraz funkcjonalnej marionetce - awatarowi gracza. Co znamienne, Martin podkreśla brak opcji modelowania postaci protagnistki poprzez znaczące wybory dialogowe; jak pisze, „główną funkcją awatara nie jest rozwój charakteru bohatera, lecz odkrywanie za jego pomocą charakteru krajobrazu”. W takim ujęciu gubi się jednak perspektywa ścisłego, funkcjonalnego połączenia estetyki i mechaniki. O ile w piątej części The Elder Scrolls konfrontacja z naturą w jej ożywionych i nieożywionych postaciach staje się kluczową częścią fabuły (zdobycie najwyższej góry w grze, Gardła Świata, jest konieczne do nauki smoczych krzyków), o tyle Oblivion posiada nieobecne już w Skyrimie umiejętności, które ową konfrontację znacznie ułatwiają: akrobatykę oraz atletykę. W piątej odsłonie The Elder Scrolls fizyczne poznawanie trudnej w eksploracji cyfrowej przestrzeni jest koniecznym warunkiem progresji fabularnej, zaś w starszych odsłonach sagi gracze przez sam proces eksploracji - obejmujący bieganie i skakanie - rozwijają narzędzia ułatwiające kontakt z cyfrową naturą. Co więcej, osiągnięcie mistrzostwa w akrobatyce pozwala w ograniczonym stopniu na chodzenie po wodzie, zaś zdobycie najwyższego stopnia zaawansowania atletyki sprawia, że bieg nie powoduje utraty wytrzymałości. Rozwój umiejętności zbliża więc podróżujące po cyfrowych krajobrazach awatary do ideału Emersonowskiego „przezroczystego oka”, czyli spojrzenia na naturę bez indiosynkratycznego skrzywienia poznawczego, ważnego również dla twórców z nurtu luminizmu (Avery, 1987, s. 15-16). Przyjemność płynąca ze zbliżenia z naturą i brak konieczności wkładania wysiłku w proces jej poznania oraz kontemplacji - czyli osiągnięcie momentu, w którym mechanika gry, określająca indywidualne uwarunkowania awatarów, nie jest już przeszkodą dla graczy chcących oddawać się eksploracji - muszą być wcześniej zdobyte $\mathrm{w}$ procesie stopniowego poznawania wymagań cyfrowej natury wobec chcących obcować z nią graczy.

Podejmując temat malarskich inspiracji w grach cRPG, można wyróżnić jego dwa podstawowe wymiary: filozoficzny oraz estetyczno-wizualny. Wskazanie pewnej ciągłości między nimi zacząć można od warstwy tematycznej. Amerykańskie szkoły malarstwa luministycznego i pejzażowego spod znaku Hudson River przedstawiały naturę jako pewne wyzwanie i granicę. Efekt osiągany był przez podkreślanie monumentalności i spójności kompozycyjnej, co dostrzec 
można szczególnie w najsłynniejszych obrazach Alberta Bierstadta, takich jak Rocky Mountain Landscape czy Among the Sierra Nevada, California. Druga, roboczo tu wyróżnioną strategią estetyczną było ukazywanie krajobrazów pogranicza z istotnym elementem obecności ludzi, którzy w jakiś sposób owo pogranicze eksplorowali, poskramiali i oswajali, zaświadczając jednocześnie o jego przynależności do specyficznie rozumianej wspólnoty kulturowej. Taką wymowę ma np. luministyczny obraz George'a Caleba Binghama Handlarze futer na Missouri, którego pierwotny tytuł, podkreślający etniczne pochodzenie ukazanych na nim postaci, został zmieniony przez ówczesną amerykańską cenzurę. Spektakularne efekty odblasków, słonecznego halo oraz gry cieni, jak również celowe skupienie na porach dnia, w których światło wydobywa z poszczególnych elementów krajobrazu niezwykłe estetyczne właściwości, miały nie tylko wywołać w widzach zachwyt, lecz również rodzaj zażyłości (intimacy; por. Guardiano, 2017, s. 86), zbliżając ich niejako do perspektywy „udomowienia” przedstawianego krajobrazu. Przenosząc ten efekt na obszar analizy gier, można doszukać się podobnych technik w graficznych sposobach przedstawiania wschodów i zachodów słońca w serii The Elder Scrolls (szczególnie Morrowind i Skyrim) czy w polskim Wiedźminie 3: Dzikim Gonie (2015).

Przechodząc do wątków filozoficznych, warto z kolei zwrócić uwagę na pracę estetyki w służbie konstruowania pewnego niezależnego - również moralnie podmiotu. Jednym z najbardziej znanych współcześnie badaczy gier zainteresowanych romantyzmem jest Daniel Vella. W swoich projektach badawczych konsekwentnie tropi on estetyczne źródła podmiotowości, a wśród produkcji realizujących ten model stwarzania doświadczenia egzystencjalnego gry poprzez estetykę podaje za przykład Dark Souls (2011). Wędrówka graczy przez cyfrowe krajobrazy ma w niej wymiar egzystencjalny, zaś fabularne zawieszenie awatara między światami ucieleśnia stan niemożliwego do jednoznacznego pozytywnego rozwiązania zawieszenia. Przeciwstawiając się popularnym w studiach nad grami tendencjom podporządkowywania estetyki zasadom retoryki proceduralnej, Vella proponuje - w duchu filozofii Jacquesa Rancière’a - odczytywać każdorazowe zetknięcie gracza z cyfrowym obiektem estetycznym jako osobny akt o znaczeniu bez mała egzystencjalnym. Odnosząc ustalenia Wolfganga Isera na temat apelatywnej struktury tekstu do analizy gier wideo, maltański badacz pisze: „Możemy zasugerować, że dokładnie takie «wydarzanie się» dotyczy również gier, z aktem grania ustanawiającym i powołującym do życia estetyczną formę" (Vella, 2015). Powoływanie się przez Vellę na estetykę recepcji, podkreślającą aktywny udział odbiorcy w konstruowaniu sensu dzieła, można odczytywać jako wyraz wiary w emergentne konstruowanie sensu gry właśnie na podstawie przeżywanego indywidualnie doświadczenia estetycznego. 
Projekt podmiotowości romantycznej - tym razem również modernistycznej - w ujęciu estetycznym był rozwijany także przez Agatę Bielik-Robson, która pisząc o „narodzinach nowożytnej indywiduacji” (Bielik-Robson, 2000, s. 25), umiejscawia ustanowienie samoświadomej jednostki właśnie w momencie jej estetycznej autokreacji. W grach cyfrowych moment ten można odnieść do ekranów tworzenia awatara, aczkolwiek o wiele istotniejsze wydaje się kreowanie postaci w jej konfrontacji ze światem. Cyfrowe światy gier cRPG operują jednak bardzo zróżnicowanymi modelami przemieszczania się i poznawania, od "turowości” po możliwą do przeprowadzania w perspektywie pierwszej osoby eksplorację w czasie rzeczywistym. Gry, które umożliwiają naprzemienną wymianę kilku perspektyw - np. pierwszo- i trzecioosobowej, jak czyni to chociażby Skyrim - uwypuklają pewien paradoks związany z wprowadzaniem w życie zarysowanego wyżej projektu romantycznej indywiduacji przez odkrywanie i spersonalizowane mapowanie dostępnej przestrzeni. Już konfrontacja z jednymi z najpowszechniejszych elementów składowych natury, jakimi są skały i kamienie, wymusza na graczach szereg rozstrzygnięć. Geologia fantastycznych cyfrowych światów niejednokrotnie opiera się właśnie na romantycznym rozumieniu tych obiektów jako „opornych” na działanie kategorii estetycznych (Heringman, 2004, s. 55), a więc wpisujących je w określony porządek. Istotny element eksploracji, jak pokonywanie łańcuchów górskich, wiąże się z potencjalnie frustrującą koniecznością wynajdywania możliwej do przemierzenia ścieżki. Choć gry z otwartym światem próbują wspierać i nagradzać graczy za eksplorację, kamienista wertykalność stanowi w tym procesie pewną przeszkodę. Widziane z daleka monumentalne wypiętrzenia geologiczne zawierają w sobie obietnice niesamowitego, lecz i opór samej materii; nawet umieszczeni w strategicznych miejscach przeciwnicy (np. potwory strzegące wąskiego gardła kanionu; w tym rozwiązaniu projektowym celowała szczególnie seria Gothic [2001-2008]) nie zawierają w sobie tak bogatej ambiwalencji znaczeniowej niepodporządkowanej prostej, kolonialnej logice konieczności pokonania „innego”. Kraina, którą widzimy, może stać się dla nas dostępna, ale stawia nam pewne wymagania przez sam fakt posiadania określonej, materialnej formy, na podstawie której gra formułuje doraźne wyzwania - to jedna z najczystszych metod funkcjonalizacji rite de passage dla graczy. Zarówno wzniosłe płótna Bierstadta oraz malarskie dokonania próbującego odgadnąć i utrwalić kosmologiczny porządek natury Frederica Edwina Churcha (Novak, 2007, s. 120), jak i bardziej oszczędne kompozycyjnie prace luministów mają rozbudzać w odbiorcach podobne odczucia: chęć eksploracji i katalogowania, zbliżonego $\mathrm{w}$ istocie do pragnienia zmapowania odwiedzanych przez widza/ gracza przestrzeni (por. Majkowski, 2019, s. 235-248). 
Kartograficzny nacjonalizm nie wyczerpuje jednak sensów ewokowanych w grach poprzez asocjacje z elementami estetyki romantycznej. Naturalne przeszkody w postaci kamiennych ścian, wąwozów czy trudnych w przeprawie rzek są istotnymi obiektami składowymi świata przedstawionego w grze - mają potencjał, aby zachwiać linearną logiką eksploracji i podporządkowywania, wyrażaną przez różnego rodzaju cyfrowe mapy (Fraser i Wilmott, 2016). Gry cRPG operujące w pełni przestrzenią 3D wyzyskują także wertykalność jako istotny element scalający indywidualne doświadczenie graczy w wymiarach optycznym i dromologicznym (por. Bartram, 2004): oto widząc potężny łańcuch górski w Skyrimie, gracz nie tylko doświadcza estetycznej przyjemności wynikającej z obserwowania go w całej okazałości z oddali, lecz później może (a w toku realizowania kolejnych zadań nawet musi) zmierzyć się z wyzwaniami związanymi z bezpośrednim przemierzaniem pokrytych nim obszarów mapy. Thomas Cole w słynnym programowym wystąpieniu Essay on American Scenery wymienił góry jako najważniejszy element lokalnego krajobrazu, opisując je jako aspekt łączący w sobie kategorie malowniczości (picturesque), wzniosłości (sublime) oraz wspaniałości (magnificence) (Cole, 1836, s. 6). Nawet produkcje cRPG oparte na silniku Infinity, wymuszającym statyczne, pseudoizometryczne obrazowanie map, chętnie operowały implikowaną wertykalnością, wyrażaną za równo na poziomie interfejsu mapy świata, jak i map poszczególnych górskich lokacji. Szczególnie przodowały w tym produkcje serii Icewind Dale, mocno podkreślające fabularne znaczenie umiejscowienia odwiedzanych przez graczy przestrzeni na osi wertykalnej (układ poziomów twierdzy Odcięta Dłoń, podróż od Przełęczy Kuldahar do Głębi Dorna). Tym, co najsilniej wyróżnia produkcje cRPG sprzed okresu popularyzacji technologii 3D, jest jednak sfera audialna i to przede wszystkim na jej obszarze dokonuje się dzisiaj reinwencja tropów ważnych dla estetyk romantyzmu.

\section{Audiosfera i dungeon synth}

Choć można znaleźć głosy, że sam termin dungeon synth (dalej w tekście: DS) wywodzi się wprost $\mathrm{z}$ opartych o eksplorację lochów gier cyfrowych, warto zaznaczyć historyczną ewolucję nazwy tego gatunku, określanego wcześniej jako dark ambient, black ambient albo dark medieval. Ostatnia z tych nazw sugeruje asocjacje z nurtem mediewalizmu, rozumianego jako konwencja luźno oparta o pewien zasób popkulturowych wyobrażeń dotyczących średniowiecza, bądź też - w nieco bardziej historycznym kontekście - rozumienie wieków średnich jako epoki inspirującej romantyków (zob. Agrawal, 1990). Nawet pobieżna kwerenda oprawy wizualnej towarzyszącej wydawnictwom spod znaku DS ujawnia proweniencję rekwizytów używanych w nich w roli swoistych znaków rozpo- 
znawczych: wykorzystanie stylizowanych rycin, figur rycerzy, elementów zbroi, uzbrojenia oraz średniowiecznej architektury obronnej składają się na łatwo rozpoznawalną estetykę. Elementami uzupełniającymi są limitowane edycje albumów utrwalone na fizycznych nośnikach, będące kluczowym elementem ważnej dla DS kultury DIY (Sowiński, 2019) - istota specyficznego doświadczenia, jakie próbują wytworzyć i przekazać twórcy tego nurtu, opiera się bowiem na całościowej koncepcji dzieła: obrazu, fizycznego przedmiotu, muzyki i towarzyszących jej odniesień (pop)kulturowych.

Jeden z pionierów gatunku, Håvard Ellefsen (znany szerzej pod pseudonimem Mortiis), wśród swoich inspiracji wymienia między innymi Tangerine Dream, twórczość Klausa Schulze czy niemieckiej formacji Kraftwerk (Klimczak, 2019, s. 83). Elektronika w połączeniu z wywiedzioną z black metalu surowością pod względem konceptualnym zbliża DS do oprawy audialnej wczesnych gier cRPG, w których muzyka miała charakter raczej ilustracyjny niż reaktywny. Wymiar temporalny wydaje się tu mniej istotny niż wymiar przestrzenny, jako że fragmenty muzyczne utrzymane w estetyce technologii 8-bitowej były sprzęgnięte raczej z daną mapą czy poziomem w grze, nie zaś z tym, co działo się akurat na ekranie w warstwie rozgrywki. Wśród najczęściej podawanych przez artystów DS inspiracji pojawiają się zarówno produkcje wydane na platformy Nintendo (takie jak Chrono Trigger [1995], Secret of Mana [1993] czy Castelvania [1986]), jak i europejskie oraz amerykańskie tytuły przeznaczone na komputery osobiste (między innymi serie Might and Magic [1986-2014] oraz Ultima [1981-2013]).

Punktem wspólnym estetyki DS oraz starszych gier cRPG jest ich oparcie na pracy symbolu i emulacji, rozumianej w tym kontekście jako naśladownictwo mające na celu przywoływanie określonych tropów kulturowych. Jednym z wyrazistych elementów estetyki audialnej twórczości spod znaku DS jest próba cyfrowego (za pomocą standardu MIDI) bądź analogowego (np. poprzez nagrywanie dźwięku z klawiatur Casio wprost na kasetę magnetofonową) odtworzenia quasi-średniowiecznej instrumentacji. DS łączy w sobie dwie sprzeczne tradycje $-\mathrm{z}$ jednej strony wprost odwołuje się do eskapistycznych elementów ewokowanych poprzez eksplorację wymyślonych światów, z drugiej zaś posiada silny nurt zwracający uwagę na mroczną podszewkę codzienności, kierującą się ku niebezpieczeństwom niesamowitego. Zakres inspiracji estetycznych tego nurtu rozciąga się gdzieś między dwoma gigantami amerykańskiej prozy fantastycznej - Howardem P. Lovecraftem i Edgarem Allanem Poe - a nieco przetworzonymi już popkulturowo inspiracjami płynącymi z fantastyki tolkienowskiej. Powracającą dominantą estetyczną okładek projektów DS są quasi-średniowieczne zamki, ukazywane często w otoczeniu dzikiej przy- 
rody; zderzenie tradycji gotycyzmu i romantyzmu następuje tu w kontekście dodatkowego wzbogacenia o elementy graficzne zaczerpnięte z rezerwuaru współczesnej twórczości fantasy. Stopniowe budowanie pejzaży dźwiękowych z warstw nakładających się na siebie ambientowych instrumentacji przypominać może estetykę amerykańskiego romantyzmu w jego mocno przetworzonej, quasi-gotyckiej wersji. W założeniach koncepcyjnych DS można doszukać się podobieństw do pisarstwa Poego, który „może być uważany za rodzaj über-Romantyka, którego specjalnością jest reifikacja topiki romantycznej, umieszczanej w obrębie gotyku" (McEvoy, 2007, s. 26). Tego typu eklektyzm przywołuje określone figury - najczęściej za pomocą odwołań do ludycznego bestiariusza znanego z popularnych systemów RPG, co może prowokować pytania o ich potencjalnie problematyczne wykorzystanie w kontekście innego medium, prowadzące na przykład do uprzedmiatawiania i seksualizacji przedstawień postaci (tak kobiecych, jak i męskich, por. Stang i Trammell, 2019). W ogólnym zarysie DS w warstwach audialnej i wizualnej pozostaje jednak daleki od konkretyzacji pomysłów narracyjnych, a zdecydowana większość twórczości tego gatunku mogłaby być wykorzystana jako tło do sesji RPG.

Atrakcyjność estetyk wizualnych wywodzących się z tradycji Szkoły Hudson realizuje się niekiedy za sprawą cytatu: na przykład okładka albumu $N a-$ ture and Solitude popularnej formacji Forest of Yore jest wykadrowaną i podkolorowaną wersją obrazu Thomasa Morana The Autumnal Woods (1865), a detale z dzieł Williama Trosta Richardsa były wykorzystywane między innymi w projekcie muzycznym Archana. Warto jednak zauważyć, że na gruncie mocno czerpiącego z gier dungeon synthu tak istotna dla Szkoły Rzeki Hudson wzniosłość zatraca nieco omawiany wcześniej rys kartograficznej dominacji; na ilustracje projektów wybierane są raczej te szkice i obrazy, które skupiają się jedynie na ewokacji indywidualnej kontemplacji natury, bez elementów sugerujących etniczny czy geograficzny kontekst lokalny. Chociaż na pewnym etapie inspiracje prerafaelickie i biblijne popchnęły niektórych amerykańskich malarzy w stronę bardziej „religijnego niesamowitego”, które współbrzmiałoby - jak pisze Barbara Novak - z „nacjonalistycznym ujęciem natury, przyczyniającym się do budowania retorycznej fasady, pod osłoną której mógł się dokonywać agresywny podbój kraju" (Novak, 2007, s. 33), wzniosłość muzyki DS czerpiącej wprost ze światów gier cyfrowych kierowałaby się raczej w stronę omawianej przez Vellę indywidualistycznej podmiotowości, czego dowodem może być niezwykła w tej niszy popularność projektów inspirowanych właśnie franczyzą Dark Souls. Albumy Disciple of the Dark Sun (2019), Sovereignless Souls (2019) oraz Downfall of Drangleic (2020) wydane pod szyldem Nameless King czy The First Flame of Lordran (2019) autorstwa amerykańskiej formacji 
Bellkeeper stanowią nie tylko komentarz, ale i twórcze rozwinięcie audiowizualnych narracji gier FromSoftware. Znamienne są sposoby nawiązania intertekstualnego dialogu ze światem Dark Souls: jest to najczęściej przywołanie występujących w grze przedmiotów (jak np. mikstury Siegbräu czy miecza Uchigatana, które stanowią tytuły utworów) bądź konkretnych lokacji (jak np. New Lando czy Firelink Shrine).

Choć DS to zjawisko zdecydowanie niszowe, blisko trzydziestoletnia historia gatunku i wspólnota doświadczeń artystycznych zaowocowały powstaniem kilku festiwali dedykowanych wyłącznie muzyce tego gatunku. Bodaj największym wydarzeniem jest trzydniowy amerykański Northeast Dungeon Siege, już w nazwie zawierający intertekstualne odwołanie do popularnej serii gier action cRPG. Projekty z gatunku DS, które wychodzą poza klasyczną bibliotekę inspiracji wywodzących się z black metalu (jak wspominany już Mortiis czy wczesne albumy Summoning) i inicjują bardziej ścisły intertekstualny dialog z grami z lat 80 . i wczesnych 90 . XX w., często wykorzystują estetykę muzyki chiptune. Realizacje powstałe w ramach tego nurtu podkreślają historyczny związek z podstawą sprzętową: 8-bitowymi komputerami, na których zakodowany dźwięk odtwarzany był w czasie rzeczywistym przez dźwiękowy układ scalony (ang. sound chip - stąd nazwa chiptune), mający najczęściej postać programowalnego generatora dźwięku (ang. programmable sound generator - w skrócie PSG) (McAlpine, 2018, s. 4). Punktem wspólnym dla obu estetyk jest niegdyś wymuszona technologicznie, później zaś przejęta jako świadomie używany element ekspresji praktyka kompozycyjna, polegająca na wykorzystywaniu często powtarzanych motywów muzycznych. Idea krótkich, kilkunastosekundowych i dobrze brzmiących w zapętleniu fragmentów muzycznych była na przykład znakiem rozpoznawczym Koji Kondo, kompozytora oprawy dźwiękowej do m.in. The Legend of Zelda (Nintendo 1986). Nawet tak oszczędny materiał artystyczny może stać się nie tylko wewnątrzgrowym tłem dla danego wycinka rozgrywki, lecz również nieść znaczenia autonomiczne bądź odsyłające do innych elementów gry. W kontekście tego japońskiego tytułu Vincent Rone przedstawiał muzykę jako czynnik „mogący odsłonić głębsze rozumienie motywów narracyjnych (...) i ich umiejscowienie w obrębie mitologii Zeldy" (Rone, 2020, s. 45-46). Z analogiczną uwagą warto traktować utwory ze ścieżki dźwiękowej gier, które mogą być z kolei interpretowane jako „zwięzte muzyczne wypowiedzi lub winiety, wyposażone $\mathrm{w}$ podstawową i uniwersalnie zrozumiałą gramatykę, bardzo efektywną w komunikowaniu skomplikowanych pomysłów oraz emocji“ (Krishnaswami, 2020, s. 70).

Swoją niszę mają również projekty łączące estetykę chiptune z dungeon synthem, jak np. album Yon Citadel J. Brewera. Inny album tego amerykańskiego 
artysty, zatytułowany wymownie Cult of the Computer God, ilustruje tendencję do komunikowania w warstwie graficznej źródeł inspiracji, a nawet kontekstu, w którym utwory mogą być odtwarzane. W przypadku Kultu komputerowego boga umieszczony na okładce napis informuje, że w środku możemy spodziewać się „science fantasy role-playing music”. Coraz częstsze przenikanie się estetyk dungeon synthu i nawiązującego do lat 80. synthwave'u otwiera perspektywę dalszej ewolucji tych gatunków, które mimo pewnych muzycznych podobieństw odwołują się do innego zbioru doświadczeń estetycznych.

Twórczość DS odznacza się również dążeniem do pewnej wewnętrznej koherencji narracyjnej, co wyraża się nie tylko w harmonijnym współwystępowaniu zbliżonych do siebie estetyk audialnych i wizualnych, ale także w nazewnictwie poszczególnych utworów. Warstwa wokalna w DS jest albo nieobecna, albo występuje w postaci sampli lub bardzo mocno przetworzonych dźwięków mających naśladować odgłosy wydawane przez różne, z reguły nieludzkie postaci. Konceptualizm albumów DS musi zatem wyrażać się w warstwach innych niż liryczna. Przykładami trzech głównych typów realizacji projektów tematycznych są albumy Sunken Dungeon (2020, projekt Longsword), Of the Men of Dor-lomin and Their Sacrifice in Nirnaeth Arnoediad (2020, Anglachel) oraz kompilacja Magickal Atavism (2019, Book of Skelos). Pierwszy z nich - zrealizowany w kluczu subgatunku dungeon noise - wykorzystuje tytuły utworów jako znaki zapowiadające wydarzenia uporządkowane chronologicznie w opowieść o ucieczce z lochu, w drugim tytuły układają się w fabularny ciąg, zbieżny z przebiegiem opisanej w Silmarillionie J.R.R. Tolkiena Bitwy Nieprzeliczonych Łez, trzeci zaś prezentuje kolaż graficznych inspiracji z użyciem stylistyk typograficznych wykorzystywanych historycznie w materiałach promocyjnych gier cRPG, nakierowując przy tym uwagę słuchacza na określone motywy za pomocą nazw poszczególnych fragmentów muzycznych.

Projekty spod znaku DS uruchamiają aktywną (re)konstrukcję nostalgii, niejako wyabstrahowując kilka wybranych elementów growego tekstu kultury (z reguły graficznych bądź muzycznych), a następnie dokonując ich twórczej rekonfiguracji. Mechanizm ten działa na zasadzie budowania poczucia przynależności i tożsamości przypisanych do określonej estetyki, podobnie jak miało to miejsce w przypadku konfrontacji człowieka z naturą w malarstwie omawianych wcześniej amerykańskich romantyków. Zbliżony proces ideologizacji estetyki w podwójnej roli - strażniczki ortodoksji oraz tekstu-wyzwania dla każdej nowej próby zmierzenia się z danym tropem kulturowym - został zauważony i opisany na przykładzie oprawy graficznej wydań podręczników RPG z serii Dungeons o Dragons (Gillespie i Crouse, 2012). 


\section{Podsumowanie}

Prezentowane w niniejszym artykule przenikanie się estetyk wizualnych romantyzmu z audialnymi inspiracjami growymi, które dopełniają i twórczo rozwijają realizowane w ich obrębie narracje, najłatwiej jest zidentyfikować na przykładach produkcji fantasy cRPG, choć ich oddziaływanie nie ogranicza się tylko do produkcji tego gatunku. Strategie projektowania interakcji w konfrontacji z elementami cyfrowego krajobrazu mogą przebiegać według scenariuszy operacjonalizacji poetyk wzniosłości i malowniczości. W takim przypadku doświadczenie estetyczne graczy rozkłada się na dwojaki typ poznania przestrzeniza pomocą pierwszego, panoramicznego oglądu niedostępnych jeszcze obszarów oraz później, już z konieczności indywidualnego mierzenia się z konkretnymi strategiami eksploracji danego wycinka cyfrowej natury. Wywiedzione z luminizmu strategie zarysowujące dychotomię etyczną za pomocą wprowadzania wyraźnego odróżnienia od siebie poszczególnych elementów estetycznych motywują wdrażanie określonych praktyk rozgrywki, takich jak kolekcjonowanie roślin czy rozwijanie umiejętności wspierających poruszanie się awatara.

Rozwiązania stosowane w utworach dungeon synthu, takie jak brak wokalu i bazowanie na pętlach, pomagają odbiorcom dopasować zawarte w nich treści do indywidualnych wyobrażeń związanych z teraźniejszym bądź przeszłym obcowaniem z historycznymi tytułami gier. Nostalgiczna podróż ewokowana przez konceptualnie zaaranżowane dźwiękowe krajobrazy ma wymiar nie tyle przypomnienia, co powtórzenia; nie jest anamnezą, ponieważ ten gatunek muzyczny jest z założenia kopią pamięci o pewnym doświadczeniu, nie zaś obietnicą dotarcia do pierwotnych odczuć, które towarzyszyły nam podczas oddalonych w czasie sesji growych.

Wizualna poetyka cyfrowych krajobrazów chętnie sięga po estetyki bliskie założeniom twórców Hudson River School: łatwo rozpoznawalne konwencje (obrazowanie panoramiczne, powtarzalny zasób rekwizytów, skala makro) idą w parze ze świadomym zawieszeniem ironii i odnowieniem wiary w epicką narrację. Krajobrazy gier fantasy cRPG w swoim monumentalizmie niejednokrotnie uzupełniają realizowaną $\mathrm{w}$ trakcie rozgrywki opowieść o transformacjach cyfrowego świata. Pastoralną wzniosłość możliwych do eksploracji, otwartych przestrzeni produkcji tego gatunku, od The Faery Tale Adventure (1987), poprzez pierwszą odsłonę Wrót Baldura (1998), aż po The Elder Scrolls V: Skyrim (2011) łączy estetyczne i filozoficzne powinowactwo z malarskimi wizjami (neo) romantycznych pejzażystów. W obu przypadkach natura jest przestrzenią działającą i zarazem domagającą się działania, zadomowienie w świecie wymaga wysiłku, a przemiany zachodzące za sprawą ludzkiej ingerencji nigdy nie naruszają 
kosmologicznego porządku stworzenia, dostępnego zmysłom w bezpośrednim obcowaniu z materią.

Jednym z punktów wspólnych projektów dungeon synthu, poetyk malarskich i estetyk growych jest przeświadczenie o intuicyjnej dostępności doznania zmysłowego. W wymiarze muzycznym przejawia się ono w czytelnym dla odbiorców, celowym zastępowaniu fizycznych instrumentów ich uproszczony$\mathrm{mi}$, elektronicznymi odpowiednikami, odwołaniem do łatwo rozpoznawalnych symboli czy operowaniem wyrazistymi estetycznymi kontrastami, obliczonymi przy tym na przywołanie bądź wykreowanie pewnej wspólnoty interpretacyjnej. Jej stawki mogą być różne: od eskapizmu, poprzez skonsolidowanie wokół wartości konotowanych przez określone estetyki, aż po retorykę legitymizującą określone postulaty polityczne. Intertekstualnej fragmentacji towarzyszy próba scalenia doświadczenia estetycznego za pomocą romantycznego Frankensteina, składającego się z anachronicznej podstawy fizycznej, celowo stylizowanej kopii technologii muzycznej oraz nawiązujących do historycznych technologii estetyk graficznych.

\section{Bibliografia:}

Agrawal, R.R. (1990). The Medieval Revival and Its Influence on the Romantic Movement. New Delhi: Abhinav Publications.

Avery, K.J. (1987). A Historiography of the Hudson River School. W: The American Paradise. The World of the Hudson River School, J.K. Howat (Ed.). New York: The Metropolitan Museum od Art.

Bartram, R. (2004). Visuality, Dromology and Time Compression: Paul Virilio's New Ocularcentrism, Time \& Society, No. 13 (2-3).

Bielik-Robson, A. (2000). Inna nowoczesność. Pytania o wspótczesna formutę duchowości. Kraków: Universitas.

Cole, T. (1836). Essay on American Scenery, The American Monthly Magazine, Vol. I.

Fraser, E., Wilmott, C. (2016). From Underground to the Sky: Navigating Verticality Through Play. W: , Playful Mapping in the Digital Age, M. Rasch (Ed.). Amsterdam: Institute of Network Cultures.

Garda, M.B. (2016). Interaktywne fantasy. Gatunek w grach cyfrowych. Łódź: Wydawnictwo Uniwersytetu Łódzkiego.

Gillespie, G., Crouse, D. (2012). There and Back again: Nostalgia, Art, and Ideology in Old-School Dungeons and Dragons, Games and Culture, No. 7(6), https://doi. org/10.1177/1555412012465004 (dostęp: 10.06.2020).

Guardiano, N.L. (2017). Aesthetic Transcendentalism in Emerson, Peirce, and NineteenthCentury American Landscape Painting. Lanham-London: Lexington Books.

Harvey, S.C. (2013). Transatlantic Transcendentalism: Coleridge, Emerson, and Nature. Edinburgh: Edinburgh University Press. 
Heringman, N. (2004). Romantic Rocks, Aesthetic Geology. Ithaca-London: Cornell University Press.

Hutchison, A. (2008). Making the Water Move: Techno-Historic Limits in the Game Aesthetics of Myst and Doom, Game Studies, No. 8(1), http://gamestudies.org/0801/articles/hutch (dostęp: 10.06.2020).

Karhulahti, V.-M. (2011). Mechanic/Aesthetic Videogame Genres: Adventure and Adventure. W: MindTrek '11: Proceedings of the 15th International Academic MindTrek Conference: Envisioning Future Media Environments. New York: Association for Computing Machinery.

Klimczak, P. (2019). Bathory w objęciach Klausa Schulze, Noise Magazine, nr X [październik, wydanie specjalne].

Krishnaswami, R. (2020). Playing Songwriter: Creating Songs for the Fictional Worlds of Video Games, Journal of Sound and Music in Games, No. 1 (2).

Majkowski, T. (2019). Język gropowieści. Studia o różnojęzyczności gier cyfrowych. Kraków: Wydawnictwo Uniwersytetu Jagiellońskiego.

Majkowski, T. (2013). W cieniu biatego drzewa. Powieść fantasy w XX wieku. Kraków: Wydawnictwo Uniwersytetu Jagiellońskiego.

Martin, P. (2011). The Pastoral and the Sublime in Elder Scrolls IV: Oblivion, Game Studies, No. 11 (3). http://gamestudies.org/1103/articles/martin (dostęp: 10.06.2020).

McAlpine, B.K. (2018). Bits and Pieces: A History of Chiptunes. Oxford: Oxford University Press.

McEvoy, E. (2007). Gothic and the Romantics. W: The Routledge Companion to Gothic, C. Spooner, E. McEvoy (Eds.). London-New York: Routledge.

Niedenthal, S. (2009). What We Talk About When We Talk About Game Aesthetics.

W: Breaking New Ground: Innovation in Games, Play, Practice and Theory. Proceedings of DiGRA 2009, http://www.digra.org/wp-content/uploads/digital-library/09287.17350.pdf (dostęp: 10.06.2020).

Novak, B. (2007). Nature and Culture. American Landscape and Painting 1825-1875 (Third). Oxford-New York: Oxford University Press.

Rone, V. (2020). History and Reception in the Music of The Legend of Zelda Peritexts, Journal of Sound and Music in Games, No. 1 (2), https://doi.org/10.1525/jsmg.2020.1.2.44 (dostęp: 10.06.2020).

Sowiński, R. (2019). Pieśni z piwnicy, czyli wstęp do dungeon synthu, Popmoderna, http://popmoderna.pl/piesni-z-piwnicy-czyli-wstep-do-dungeon-synthu/ (dostęp: 10.06.2020).

Stang, S., Trammell, A. (2019). The Ludic Bestiary: Misogynistic Tropes of Female Monstrosity in Dungeons \& Dragons, Games and Culture, Vol. 15, https://doi.org/10.1177/1555412019850059 (dostęp: 10.06.2020).

Vargas-Iglesias, J.J. (2020). Making Sense of Genre: The Logic of Video Game Genre Organization, Games and Culture, No. 15 (2), https://doi.org/10.1177/1555412017751803 (dostęp: 10.06.2020).

Vella, D. (2015). No Mastery Without Mystery: Dark Souls and the Ludic Sublime, Game Studies, No. 15 (1), http://gamestudies.org/1501/articles/vella (dostęp: 10.06.2020). 


\section{Ludografia:}

Baldur's Gate (1998, BioWare).

Castelvania. (1986, Konami).

Chrono Trigger (1995, Square).

Dark Souls (2011, FromSoftware).

Dragon Age: Inquisition (2011, BioWare).

Gothic (2001, Piranha Bytes).

Icewind Dale (2000, Black Isle Studios).

Might and Magic V: Darkside of Xeen (1993, New World Computing).

Pillars of Eternity (2015, Obsidian Entertainment).

Secret of Mana (1993, Square).

The Elder Scrolls III: Morrowind (2002, Bethesda Game Studios).

The Elder Scrolls IV: Oblivion (2006, Bethesda Game Studios).

The Elder Scrolls V: Skyrim (2011, Bethesda Game Studios).

The Faery Tale Adventure (1987, Microlllusions).

The Legend of Zelda (1986, Nintendo EAD).

Ultima IV: Quest of the Avatar (1985, Origin Systems).

Wiedźmin 3: Dziki Gon (2015, CD Projekt Red). 


\section{Summary:}

The aim of this text is to discern and analyze aesthetic tropes in selected fantasy cRPG games in the areas of visual arts and music. The analysis is conducted in the context of American romanticism, especially Hudson River School of painting, and musical works belonging to the dungeon synth genre. Through the enumeration and close reading of the elements pertaining both gameplay and digital landscapes, it is argued that the specific type of romantic imagery and its philosophical underpinnings may have influenced the recurring themes in cRPG games, including character development, avatar's agency and player's projected disposition towards the game world.

Keywords: aesthetics, cRPG, romanticism, landscape painting, music, dungeon synth 